Article

\title{
Design of a Wide-Band Microstrip Filtering Antenna with Modified Shaped Slots and SIR Structure
}

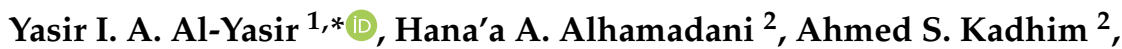 \\ Naser Ojaroudi Parchin ${ }^{1}\left(\mathbb{D}\right.$, Ameer L. Saleh ${ }^{3} \mathbb{D}$, Issa T. E. Elfergani ${ }^{4} \mathbb{D}$, Jonathan Rodriguez ${ }^{4}(\mathbb{D}$ \\ and Raed A. Abd-Alhameed ${ }^{1}$ (D) \\ 1 Biomedical and Electronics Engineering, Faculty of Engineering and Informatics, University of Bradford, \\ Bradford BD7 1DP, UK; N.OjaroudiParchin@bradford.ac.uk (N.O.P.); R.A.A.Abd@bradford.ac.uk (R.A.A.-A.) \\ 2 Electronic Techniques Department, Basra Technical Institute, Southern Technical University, Basra 61001, \\ Iraq; hnaa.abdulrazzaq@stu.edu.iq (H.A.A.); Ahmedsabri1988@gmail.com (A.S.K.) \\ 3 Department of Electrical Engineering, University of Misan, Misan 62001, Iraq; ameer-lateef@uomisan.edu.iq \\ 4 Instituto de Telecomunicações, Campus Universitário de Santiago, 3810-193 Aveiro, Portugal; \\ I.t.e.elfergani@av.it.pt (I.T.E.E.); Jonathan@av.it.pt (J.R.) \\ * Correspondence: y.i.a.al-yasir@bradford.ac.uk; Tel.: +44-127-423-8047
}

Received: 31 December 2019; Accepted: 18 February 2020; Published: 24 February 2020

check for updates

\begin{abstract}
This paper presents a new compact microstrip filtering antenna with modified shaped slots to improve the impedance bandwidth. The proposed microstrip filtering antenna consists of three parts: the monopole radiating patch antenna; the Stepped Impedance Resonator (SIR) filter; and the feeding microstrip line. The designed structure is achieved on one-sided glass epoxy FR-4 substrate with dielectric constant $\varepsilon_{\mathrm{r}}=4.4$ and thickness $\mathrm{h}=1.6 \mathrm{~mm}$. The design procedure of the proposed filtering antenna starts from the second-order Chebyshev low pass filter (LPF) prototype. The achieved results show an excellent performance of S11-parameter with broadside antenna gain on $+z$-direction. Having two transmission zeros at $5.4 \mathrm{GHz}$ and $7.7 \mathrm{GHz}$, good skirt selectivity and a wide-band impedance bandwidth of about $1.66 \mathrm{GHz}$ makes the designed filtering antenna suitable for high-speed data communications. Both the simulation results generated by using the Computer Simulation Technology (CST) software package and the measurement achieved by using a vector network analyzer (HP 8510C) and the anechoic chamber show good agreement.
\end{abstract}

Keywords: microstrip filtering antenna; impedance bandwidth; FR-4; computer simulation technology; Chebyshev; LPF

\section{Introduction}

Increasing demand for compact transceiver applications continues to affect the field of microwave and radio frequency communications [1-4]. Some of the most important modules in such systems are the microstrip antennas and filters [5-40]. Microstrip Patch Antenna (MPA) has been designed and widely characterized a few years ago for several reasons, the most important was that it had a low profile, was lightweight and had a low fabrication cost [18]. Different techniques have been developed in order to achieve rapid solutions to enhance radiation specifications such as bandwidth and gain. The radiating patch can assume any possible geometry, including a rectangle, circle, square, dipole and triangle [19]. The microstrip monopole patch antenna is designed as a single-layer which usually consists of four parts: patch, a dielectric substrate, half ground plane and feedline [20]. Generally, the physical dimensions of a microstrip monopole patch antenna are small, but the electrical dimensions measured in wavelength $\lambda$ are not small [21]. The designers of the microstrip antennas should also consider the electrical characteristics of these antennas such as center frequency $\mathrm{f}_{0}$, voltage standing 
wave ratio (VSWR), return loss, gain and radiation pattern [22]. Rapid data transfer requires high channel capacities and needs more complex and bulky systems. Modern trends in electronic and communication systems proposed more compact and portable systems, therefore the designers of such systems faced a major challenge in realizing these complex systems and at the same time making them compact and portable enough to meet commercial market needs [23]. One way to minimize the overall circuit size and increase the bandwidth is to integrate the Stepped Impedance Resonator (SIR) filter with the monopole patch antenna in one single module [24]. This integration changes the structure of the circuit, improves the performance of the circuit and simplifies the connection among various components.

Unlike many microstrip filtering antenna proposed in the literature [35-44], the design proposed here is better than others with respect to the structure size, design complexity, gain, bandwidth and the reflection coefficient characteristics. Also, this paper presents a compact second-order filtering antenna utilizing SIR and modified shaped slots on the monopole patch antenna. By using SIR bandpass filter and adopting the modified shaped slots on the monopole patch antenna, the performance of the circuit has been improved, especially the bandwidth performance.

\section{Design of the Filtering Antenna}

The 3-D view of the proposed microstrip filtering antenna is described in Figure 1. The designed structure is printed on one side of a glass epoxy FR-4 substrate with dielectric constant $\varepsilon_{r}=4.4$ and thickness $h=1.6 \mathrm{~mm}$. The microstrip filtering antenna consists of three parts: the monopole radiating patch antenna, the SIR filter and the feeding microstrip line. The monopole patch antenna has dimensions of $\mathrm{w}_{\mathrm{p}} \times \mathrm{l}_{\mathrm{p}}$, with $\mathrm{l}_{\mathrm{p}}$ about $0.863 \lambda_{\mathrm{g}}$ at the operating frequency.

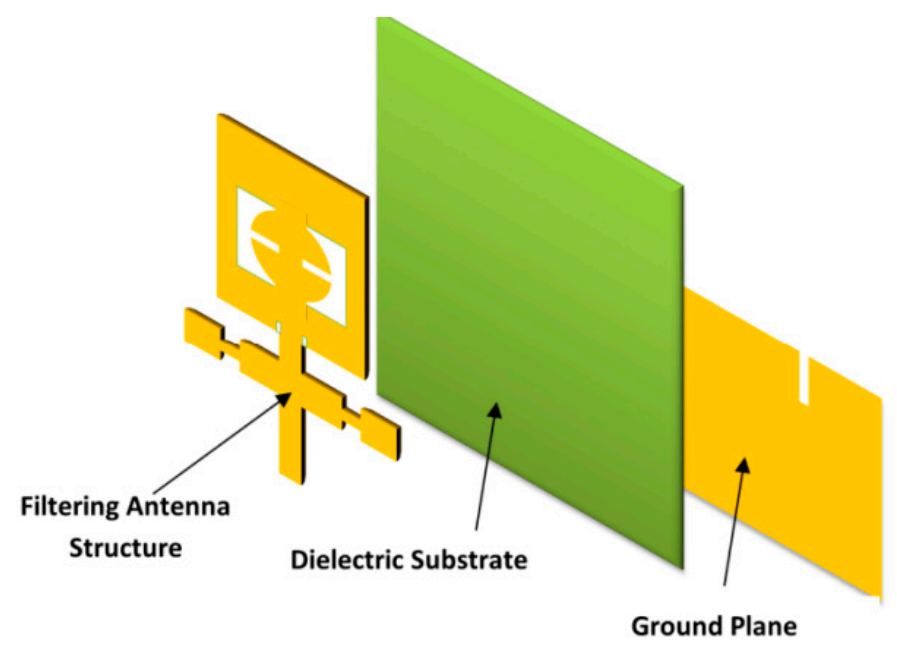

Figure 1. 3-D view structure of the proposed filtering antenna.

Notably, the equivalent circuit of the proposed filtering antenna is the same as the bandpass filter prototype. By utilizing the filter synthesis technique, the filtering antenna can be designed along with the filter response. The design procedure of the proposed filtering antenna starts from the second-order Chebyshev low pass filter prototype. The design parameters such as the center frequency, the fractional bandwidth (FBW), return loss and insertion loss are calculated and discussed. The lumped element values of the microwave circuit model shown in Figure 2a are available in the literature [23]. The following step is to design the resonator via the SIR structure and with a modified slot-shaped monopole patch antenna. Finally, the filter and antennas are integrated with fine-tuning to improve the performance. The simulation results throughout this research paper are accomplished by using Computer Simulation Technology (CST) software [25] and the measurement results are achieved using the vector network analyzer (HP 8510C) and an anechoic chamber. The designed structure 
with its optimized dimensions and photograph of the fabricated prototype for the proposed filtering antenna are presented in Figure 2 and Table 1.

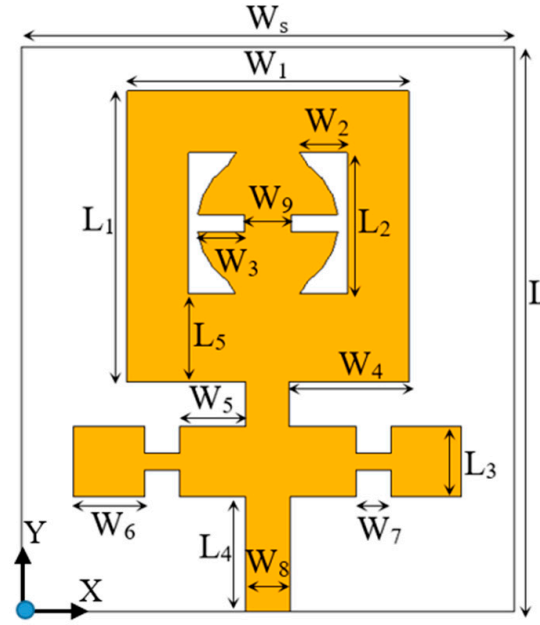

(a)

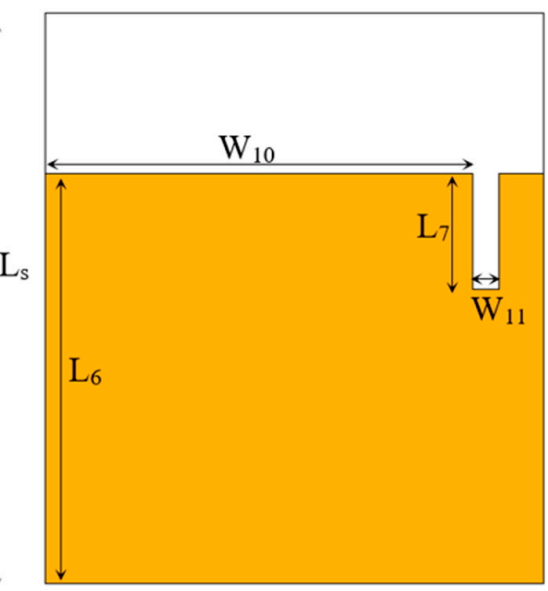

(b)

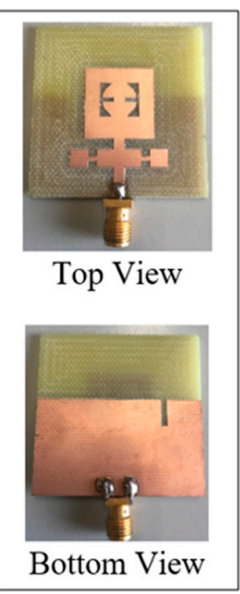

(c)

Figure 2. Geometry of the proposed filtering antenna with its optimized dimensions: (a) Top view (b) Bottom view (c) Photograph of the hardware realization.

Table 1. The optimized dimensions of the proposed filtering antenna (in $\mathrm{mm}$ ).

\begin{tabular}{lccccccccc}
\hline Parameter $\mathbf{W}_{\mathbf{1}}$ & $\mathbf{W}_{\mathbf{2}}$ & $\mathbf{W}_{\mathbf{3}}$ & $\mathbf{W}_{\mathbf{4}}$ & $\mathbf{W}_{\mathbf{5}}$ & $\mathbf{W}_{\mathbf{6}}$ & $\mathbf{W}_{\mathbf{7}}$ & $\mathbf{W}_{\mathbf{8}}$ & $\mathbf{W}_{\mathbf{9}}$ & $\mathbf{W}_{\mathbf{1 0}}$ \\
\hline Dimensions16 & 2.6 & 2.6 & 6.8 & 3.7 & 4 & 2 & 2.5 & 24 & 1.5 \\
Parameter $\mathbf{W}_{\mathbf{1 1}}$ & $\mathbf{L}_{\mathbf{1}}$ & $\mathbf{L}_{\mathbf{2}}$ & $\mathbf{L}_{\mathbf{3}}$ & $\mathbf{L}_{\mathbf{4}}$ & $\mathbf{L}_{\mathbf{5}}$ & $\mathbf{L}_{\mathbf{6}}$ & $\mathbf{L}_{\mathbf{7}}$ & $\mathbf{W}_{\mathbf{s}}$ & $\mathbf{L}_{\mathbf{s}}$ \\
\hline Dimensions1.5 & 16.5 & 8 & 4 & 6.5 & 5 & 23 & 6.5 & 28 & 30 \\
\hline
\end{tabular}

The proposed filtering antenna shown in Figure 2 can be expressed by its equivalent circuits, as seen in Figure 3a. The equivalent circuit of the proposed filtering antenna is transferred to the conventional second-order bandpass filter equivalent circuits and can be implemented as shown in Figure $3 b$ [26]. The SIR and monopole patch antenna are modeled by parallel $L_{1} C_{1}$ [27] and $L_{A} C_{A}$ $R_{A}$ [28] lumped elements, respectively. According to the filter synthesis approach theory [29], the SIR is considered as a first stage resonator and the monopole patch antenna as the second stage resonator with an appropriate load impedance of $\mathrm{R}_{\mathrm{A}}$.

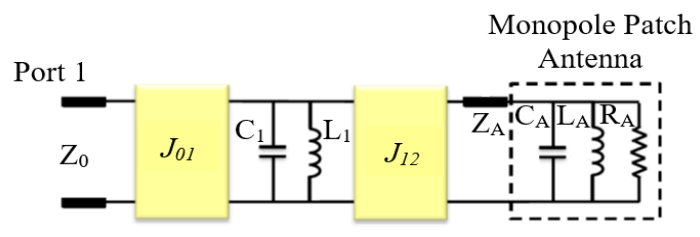

(a)

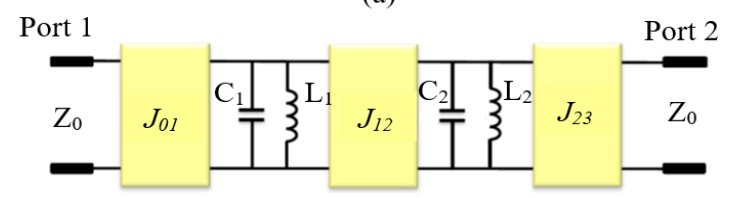

(b)

Figure 3. Microwave equivalent circuit: (a). The proposed filtering antenna (b). The second-order bandpass filter. 
The resistance $R_{A}$ in the equivalent circuit of the monopole patch antenna is considered as the load impedance of the bandpass filter to be synthesized, and the parallel $\mathrm{L}_{\mathrm{A}} / \mathrm{C}_{\mathrm{A}}$ is the last circuit resonator of the filtering antenna. Then:

$$
\mathrm{f}_{\mathrm{o}}=\frac{1}{2 \pi \sqrt{\mathrm{L}_{\mathrm{A}} \mathrm{C}_{\mathrm{A}}}} .
$$

The second-order bandpass filter is chosen as a Chebyshev equal-ripple response, with the ripple level $\mathrm{L}_{\mathrm{A}}(\mathrm{dB})=0.5, f_{o}=6.45 \mathrm{GHz}$, and port characteristic impedance of $\mathrm{Z}_{\mathrm{o}}=50 \Omega$. The minimum return loss $R_{L}(d B)$ in passband for an ideal Chebyshev bandpass filter is given as [30]:

$$
\mathrm{R}_{\mathrm{L}}(\mathrm{dB})=-10 \log \left(1-10^{-\mathrm{L}_{\mathrm{A}}(\mathrm{dB}) / 10}\right)
$$

where, $\mathrm{R}_{\mathrm{L}}=-18.2 \mathrm{~dB}$, and the FBW $=25.7 \%$.

The quality factor is one of the most critical parameters of the resonant circuit, and increasing its value means that lower loss in the resonant circuit will be achieved. The quality factor of the monopole patch antenna can be derived from the equivalent circuit of the proposed filtering antenna shown in Figure 3(a), and it is used for synthesizing the filtering antenna [31]:

$$
\mathrm{Q}_{\mathrm{A}}=\frac{2 \pi \mathrm{f}_{\mathrm{o}} \mathrm{L}_{\mathrm{A}}}{\mathrm{R}_{\mathrm{A}}} .
$$

The values of LC components of the resonators are given by:

$$
\begin{aligned}
& \mathrm{L}=\frac{2 \mathrm{Z}_{\mathrm{o}}}{\pi \mathrm{f}_{\mathrm{o}}} \\
& \mathrm{C}=\frac{1}{\mathrm{Lf_{ \textrm {O } } ^ { 2 }} .}
\end{aligned}
$$

After solving the above equations, $\mathrm{L}$ and $\mathrm{C}$ are found to be $4.93 \mathrm{nH}$ and $4.87 \mathrm{Pf}$, respectively.

According to the above, for the second-order $(\mathrm{N}=2)$ Chebyshev low pass filter prototype with a passband ripple of $0.5 \mathrm{~dB}$, the element values are $\mathrm{g}_{\mathrm{o}}=1, \mathrm{~g}_{1}=1.4029, \mathrm{~g}_{2}=0.7071$ and $\mathrm{g}_{3}=1.9841$. Generally, for the equivalent circuit of the bandpass filter shown in Figure $3 b$, the theoretical values of the J-inverters can be readily obtained [32] as follows:

$$
\begin{aligned}
\mathrm{J}_{01} & =\frac{1}{\mathrm{Z}_{\mathrm{o}}} \sqrt{\frac{\pi \mathrm{FBW}}{4 \mathrm{~g}_{\mathrm{o}} \mathrm{g}_{1}}} \\
\mathrm{~J}_{\mathrm{n}-1, \mathrm{n}} & =\frac{1}{\mathrm{Z}_{\mathrm{o}}} \frac{\pi \mathrm{FBW}}{4 \sqrt{\mathrm{g}_{\mathrm{n}-1} \mathrm{~g}_{\mathrm{n}}}} .
\end{aligned}
$$

The second-order Chebyshev bandpass filter parameter values are summarized in Table 2.

Table 2. Second-order Chebyshev bandpass filter parameters.

\begin{tabular}{cc}
\hline Parameter & Value \\
\hline FBW & 0.257 \\
$\mathrm{~g}_{\mathrm{o}}$ & 1 \\
$\mathrm{~g}_{1}$ & 1.4029 \\
$\mathrm{~g}_{2}$ & 0.7071 \\
$\mathrm{~g}_{3}$ & 1.9841 \\
$\mathrm{~J}_{01}$ & $7.48 \times 10^{-3}$ \\
$\mathrm{~J}_{12}$ & $4.688 \times 10^{-3}$ \\
$\mathrm{~J}_{23}$ & $3.942 \times 10^{-3}$ \\
\hline
\end{tabular}




\section{Simulation and Measurement Results and Discussion}

Defected ground structure (DGS) was commonly used in the microstrip filters and antennas to improve the S-parameters performance and achieve compact size structure [33]. The realization of the DGS is performed by inserting a defected shape on the ground plane to disturb the current shield distribution. Establish the shape and dimensions of the DGS, following which the disturbance at the ground shield current distribution controls the current flow and the input impedance of the proposed filtering antenna [34]. The excitation of the electromagnetic waves that propagate inside the dielectric substrate layer can also be controlled by the DGS. The S11-parameter of the proposed filtering antenna with and without DGS is shown in Figure 4. Recently, the DGS was used to enhance the stop-band rejection characteristics as illustrated in Figure 4. Figure 5 shows the S11-parameter of the proposed filtering antenna for different shaped slots loaded.

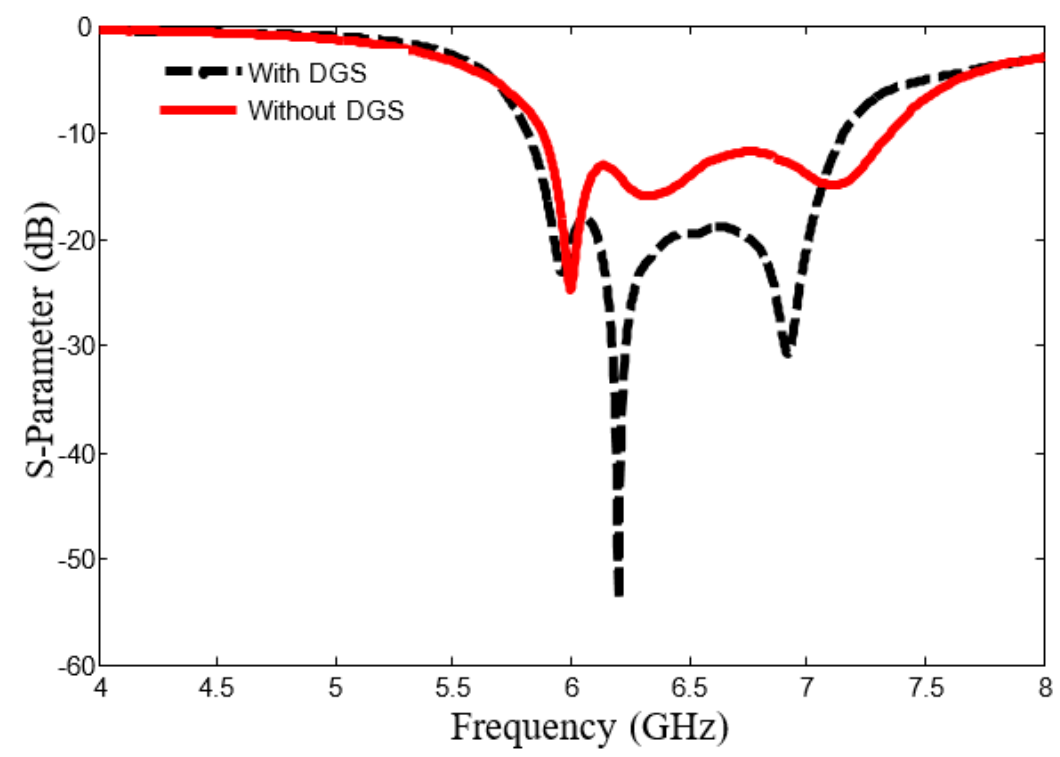

Figure 4. S11-parameter of the proposed filtering antenna with and without defected ground structure (DGS).

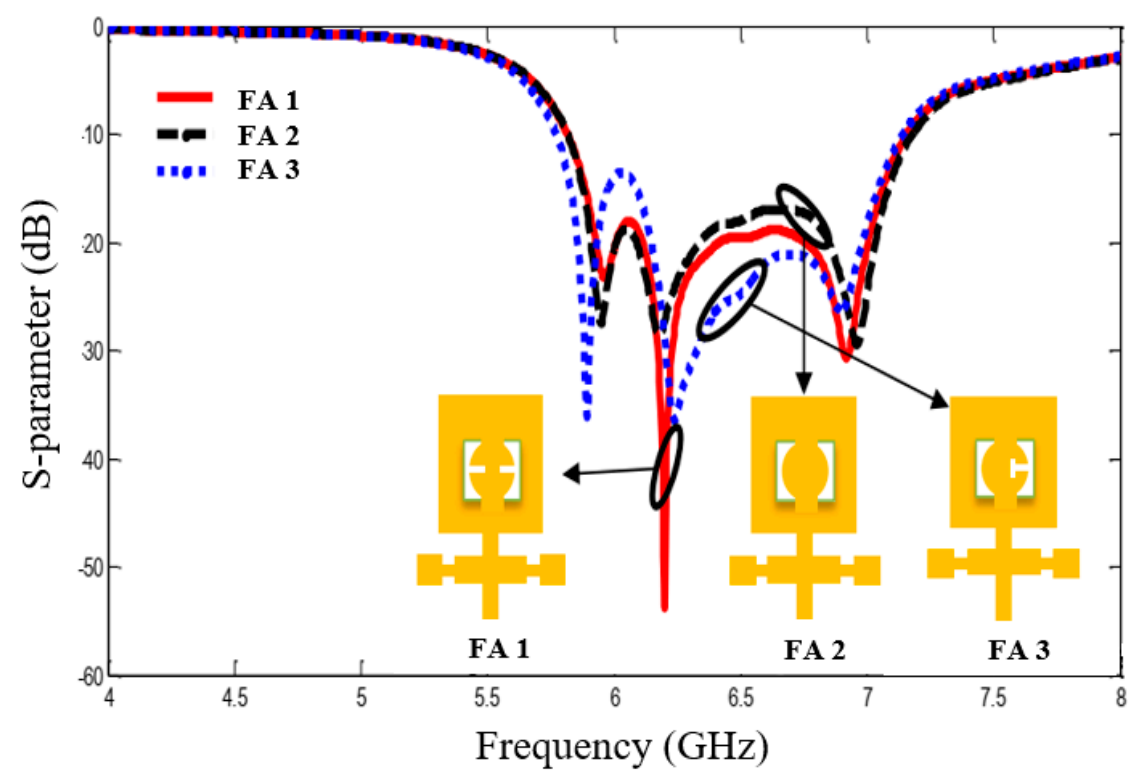

Figure 5. S11-parameter of the proposed filtering antenna (FA) for different shaped slots. 
The performance of the proposed filtering antenna, in terms of return losses, radiation patterns and gains, have been studied and measured. The simulated and measured S11-parameter and gain of the proposed filtering antenna are shown in Figure 6. Based on these results, it is found that at the center frequency $\mathrm{f}_{\mathrm{o}}=6.45 \mathrm{GHz}$, the filtering antenna has two transmission zeros at $5.4 \mathrm{GHz}$ and $7.7 \mathrm{GHz}$, with impedance bandwidth (BW) of about $1.66 \mathrm{GHz}$. Broadband is one of the most important requirements for modern digital communication, which requires transmitting and receiving a huge bit rate. Therefore, this design is suitable for high-speed data communication.

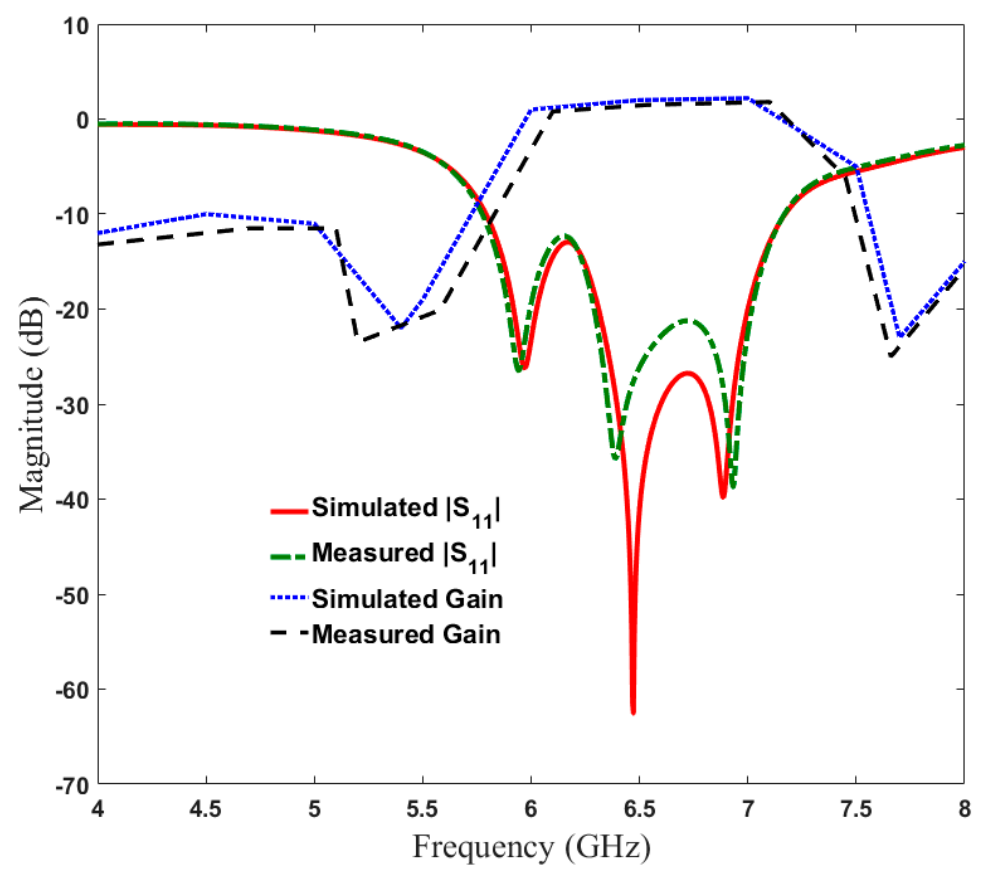

Figure 6. S11-parameter and gain of the proposed filtering antenna.

Figure 7 shows the measured and simulated radiation patterns of the proposed filtering antenna at the resonant frequency. Full-wave simulation is carried out using CST software and the measurement radiation pattern is observed inside the anechoic chamber. $\mathrm{E} \phi$ represents the co-polarization properties, while E $\theta$ represents the cross-polarization properties. The yz-coordinates are taken into account as the E-plane, and the xz-coordinates as the H-plane.

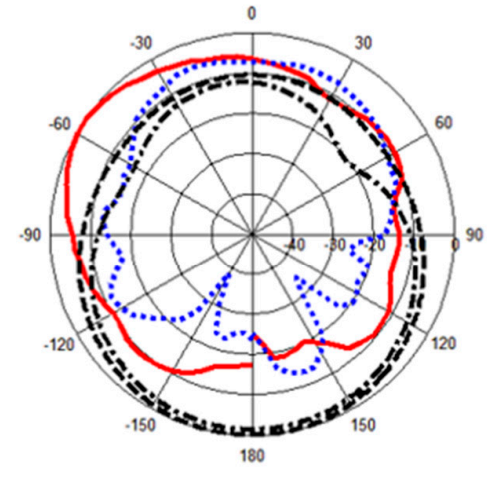

(a)

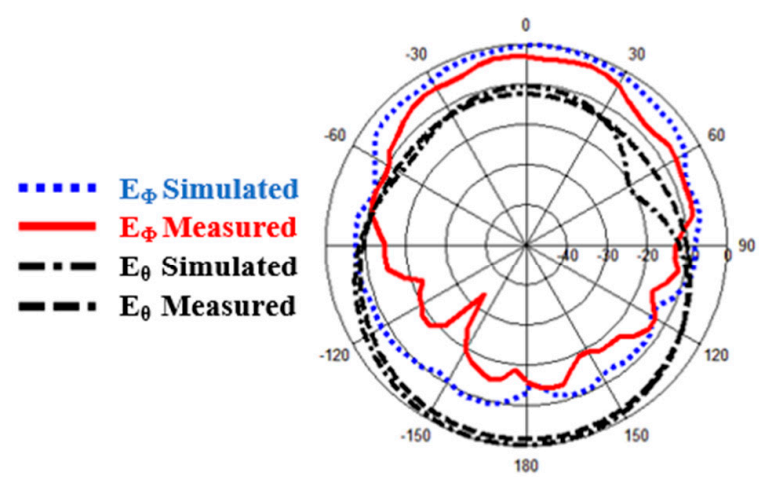

(b)

Figure 7. Simulated and measured radiation patterns for the proposed filtering antenna (a) xz plane, and (b) yz plane. 
The simulated and measured radiation pattern characteristics of the filtering antenna are roughly invariant, with a good performance of the S11-parameter and broadside antenna gain on $+z$-direction. The peak gain of the achieved pattern is about $3 \mathrm{~dB}$, which provides good skirt selectivity. Both the simulation results generated by using the CST software package and the measurement achieved from the vector network analyzer (HP 8510C) and anechoic chamber show fairly good agreement. Variations between the simulated and measured results may arise due to the connection of the antenna to the non-ideal absorber by coaxial cable in the anechoic chamber. Table 3 compares this proposed microstrip filtering antenna with other designs that have similar configurations and performances. The design proposed here is better than others with respect to the structure size, design complexity, gain, bandwidth and the reflection coefficient characteristics.

Table 3. Comparison between the proposed design and others.

\begin{tabular}{ccccccc}
\hline Ref. & CF (GHz) & $\begin{array}{c}\text { 3 dB Fractional } \\
\text { Bandwidth (\%) }\end{array}$ & Size $\left(\boldsymbol{\lambda}_{\mathbf{g}} \times \boldsymbol{\lambda}_{\mathbf{g}}\right)$ & RL (dB) & Gain (dB) & $\begin{array}{c}\text { Extra } \\
\text { Structure }\end{array}$ \\
\hline$[35]$ & 2.5 & 15 & $11 \times 11$ & $>15$ & 2 & Multi-layer \\
{$[36]$} & 5 & 2 & $1.3 \times 1.13$ & $>15$ & 4 & None \\
{$[37]$} & 2.45 & 6.4 & $9.7 \times 9.5$ & $>15$ & 6 & None \\
{$[38]$} & 2.5 & 16.3 & $0.8 \times 0.5$ & $>20$ & 2.4 & None \\
{$[39]$} & 2.5 & 8 & $6 \times 6$ & $>14$ & 4.5 & None \\
Prop. & 6.5 & 30 & $1.2 \times 1$ & $>30$ & 3 & None \\
\hline
\end{tabular}

\section{Conclusions}

A new and compact filtering antenna with modified shaped slots has been designed, fabricated and measured in a microstrip transmission line. The proposed filtering antenna was analyzed by utilizing the filter synthesis approach and based on the equivalent circuit and specifications of the second-order Chebyshev low pass filter. The proposed filtering antenna structure with the SIR technique provides good skirt selectivity. The design shows good performance and is suitable for high-speed communication applications. Both the simulation results generated by using the CST software package and the measurement achieved by the vector network analyzer and anechoic chamber show good agreement.

Author Contributions: Conceptualization, Y.I.A.A.-Y., H.A.A., A.S.K.; methodology, Y.I.A.A.-Y. and N.O.P.; investigation, Y.I.A.A.-Y., H.A.A., I.T.E.E., J.R., A.L.S. and R.A.A.-A.; resources, Y.I.A.A.-Y., N.O.P, A.S.K. and R.A.A.-A.; writing-original draft preparation, Y.I.A.A.-Y., H.A.A., A.S.K, A.L.S., I.T.E.E., R.A.A.-A. and J.R.; writing-review and editing, Y.I.A.A.-Y., H.A.A., N.O.P. and I.T.E.E.; visualization, Y.I.A.A.-Y., A.S.K., I.T.E.E., R.A.A.-A. and J.R. All authors have read and agreed to the published version of the manuscript.

Funding: This project has received funding from the European Union's Horizon 2020 research and innovation program under grant agreement H2020-MSCA-ITN-2016 SECRET-722424.

Acknowledgments: The authors wish to express their thanks to the support provided by the innovation program under grant agreement H2020-MSCA-ITN-2016 SECRET-722424.

Conflicts of Interest: The authors declare no conflict of interest

\section{References}

1. Hussaini, A.; Al-Yasir, Y.I.A.; Voudouris, K.; Mohammed, B.; Abd-Alhameed, R.; Mohammed, H.; Elfergani, I.; Abdullah, A.; Makris, D.; Rodriguez, J.; et al. Green Flexible RF for 5G. In Fundamentals of 5G Mobile Networks, 1st ed.; Rodriguez, J., Ed.; John Wiley and Sons: Hoboken, NJ, USA, 2015.

2. Al-Yasir, Y.; Abdullah, A.; Ojaroudi Parchin, N.; Abd-Alhameed, R.; Noras, J. A New PolarizationReconfigurable Antenna for $5 \mathrm{G}$ Applications. Electronics 2018, 7, 293. [CrossRef]

3. Liu, H.W.; Ren, B.P.; Li, S.; Guan, X.H.; Wen, P.; Peng, X.X.Y. High-Temperature Superconducting Bandpass Filter Using Asymmetric Stepped-Impedance Resonators with Wide-Stopband Performance. IEEE Trans. Appl. Supercond. 2015, 25, 1-6. 
4. Al-Yasir, Y.I.A.; Parchin, N.O.; Abdulkhaleq, A.; Abd-Alhameed, R.; Noras, J. Recent Progress in the Design of 4G/5G Reconfigurable Filters. Electronics 2019, 8, 114. [CrossRef]

5. Abdulraheem, Y.I.; Abdullah, A.; Mohammed, H.; Abd-Alhameed, R.; Noras, J. Design of Frequency-reconfigurable Multiband Compact Antenna using two PIN diodes for WLAN/WiMAX Applications. IET Microw. Antennas Propag. 2017, 11, 1098-1105. [CrossRef]

6. Mohammed, H.J.; Abdulsalam, F.; Abdulla, A.S.; Ali, R.S.; Abd-Alhameed, R.A.; Noras, J.M.; Abdulraheem, Y.I.; Ali, A.; Rodriguez, J.; Abdalla, A.M. Evaluation of genetic algorithms, particle swarm optimisation, and firefly algorithms in antenna design. In Proceedings of the 13th International Conference on Synthesis, Modeling, Analysis and Simulation Methods and Applications to Circuit Design (SMACD), Lisbon, Portugal, 27-30 June 2016; pp. 1-4.

7. Al-Yasir, Y.; Abd-Alhameed, R.A.; Noras, J.M.; Abdulkhaleq, A.M.; Parchin, N.O. Design of very compact combline band-pass filter for 5G applications. In Proceedings of the Loughborough Antennas \& Propagation Conference (LAPC 2018), Loughborough, UK, 12-13 November 2018; pp. 1-4.

8. Abdel-Jabbar, H.; Kadhim, A.S.; Saleh, A.L.; Al-Yasir, Y.I.A.; Parchin, N.O.; Abd-Alhameed, R.A. Design and optimization of microstrip filtering antenna with modified shaped slots and SIR filter to improve the impedance bandwidth. TELKOMNIKA Telecommun. Comput. Electron. Contro 2020, 18, 515-545. [CrossRef]

9. Al-Yasir, Y.I.A.; Tu, Y.; Parchin, N.O.; Elfergani, I.; Abd-Alhameed, R.; Rodriguez, J.; Noras, J. Mixed-coupling multi-function quint-wideband asymmetric stepped impedance resonator filter. Microw. Opt. Tech. Lett. 2019, 61, 1181-1184. [CrossRef]

10. Mabrok, M.; Zahriladha, Z.; Masrukin, E.; Sutikno, T.; Othman, A.R.; Nurhasniza, E. Switchable Dual-band Bandpass Filter Based on Stepped Impedance Resonator with U-Shaped Defected Microstrip Structure for Wireless Applications. TELKOMNIKA Telecommun. Comput. Electron. Control 2019, 17, 1032-1039. [CrossRef]

11. Al-Yasir, Y.I.A.; Tu, Y.; Bakr, M.S.; Parchin, N.O.; Asharaa, A.S.; Mshwat, W.A.; Abd-Alhameed, R.A.; Noras, J.M. Design of multi-standard single/tri/quint-wideband asymmetric stepped-impedance resonator filters with adjustable TZs. IET Microw. Antennas Propag. 2019, 13, 1637-1645. [CrossRef]

12. Al-Yasir, Y.I.A.; Tu, Y.; Parchin, N.O.; Abdulkhaleq, A.; Kosha, J.; Ullah, A.; Abd-Alhameed, R.; Noras, J. New Multi-standard Dual-Wideband and Quad-Wideband Asymmetric Step Impedance Resonator Filters with Wide Stop Band Restriction. Int. J. RF Microw. Comput. Aided Eng. 2019, 29, 1-17. [CrossRef]

13. Al-Yasir, Y.I.A.; Parchin, N.O.; Alabdallah, A.; Abdulkhaleq, A.M.; Abd-Alhameed, R.A.; Noras, J.M. Design of Bandpass Tunable Filter for Green Flexible RF for 5G. In Proceedings of the 2019 IEEE 2nd 5G World Forum (5GWF), Dresden, Germany, 30 September-2 October 2019; pp. 194-198.

14. Mohsen, M.K.; Isa, M.S.M.; Isa, A.A.M.; Abdulhameed, M.K. Enhancement of boresight radiation for leaky wave antenna array. TELKOMNIKA Telecommun. Comput. Electron. Control 2019, 17, 2179-2185. [CrossRef]

15. Al-Yasir, Y.I.A.; Parchin, N.O.; Alabdallah, A.; Abdulkhaleq, A.M.; Sajedin, M.; Elfergani, I.T.E.; Abd-Alhameed, R.A. Design, Simulation and Implementation of Very Compact Open-loop Trisection BPF for 5G Communications. In Proceedings of the 2019 IEEE 2nd 5G World Forum (5GWF), Dresden, Germany, 30 September-2 October 2019; pp. 189-193.

16. Al-Yasir, Y.; OjaroudiParchin, N.; Abdulkhaleq, A.; Hameed, K.; Al-Sadoon, M.; Abd-Alhameed, R. Design, Simulation and Implementation of Very Compact Dual-band Microstrip Bandpass Filter for 4G and 5G Applications. In Proceedings of the 2019 16th International Conference on Synthesis, Modeling, Analysis and Simulation Methods and Applications to Circuit Design (SMACD), Lausanne, Switzerland, 15-18 July 2019; pp. 41-44.

17. Al-Yasir, Y.I.A.A.; JaroudiParchin, N.O.; Alabdullah, A.; Mshwat, W.; Ullah, A.; Abd-Alhameed, R. New Pattern Reconfigurable Circular Disk Antenna Using Two PIN Diodes for WiMax/WiFi (IEEE 802.11 a) Applications. In Proceedings of the 2019 16th International Conference on Synthesis, Modeling, Analysis and Simulation Methods and Applications to Circuit Design (SMACD), Lausanne, Switzerland, 15-18 July 2019; pp. 53-56.

18. Jain, A.; Agrawal, A. Design and Optimization of a Microstrip Patch Antenna for Increased Bandwidth. Int. J. Electr. Comput. Energetic Electron. Commun. Eng. 2013, 7, 191-195.

19. Kumar, R.; Dhubkarya, D. Design and analysis of circular ring microstrip antenna. Glob. J. Res. Eng. 2011, 11, $1-5$.

20. Paul, L.C.; Sultan, N. Design, simulation and performance analysis of a line feed rectangular micro-strip patch antenna. Int. J. Eng. Sci. Emerg. Technol. 2013, 4, 117-126. 
21. Boualleg, A.; Merabtine, N. Analysis of radiation patterns of rectangular microstrip antennas with the uniform substrate. Semicond. Phys. Quantum Electron. Optoelectron. 2005, 8, 88-91. [CrossRef]

22. Liu, H.-W.; Ku, C.-H.; Yang, C.-F. Novel CPW-fed planar monopole antenna for WiMAX/WLAN applications. IEEE Antennas Wirel. Propag. Lett. 2010, 9, 240-243. [CrossRef]

23. Naeem, U.; Bila, S.; Verdeyme, S.; Thévenot, M.; Monédière, T. A compact dual band filter-antenna subsystem for 802. In $11 \mathrm{Wi}-\mathrm{Fi}$ applications. In Proceedings of the Wireless Technology Conference (EuWIT), 2010 European, Paris, France, 27-28 September 2010; pp. 181-184.

24. Zuo, J.; Chen, X.; Han, G.; Li, L.; Zhang, W. An integrated approach to RF antenna-filter co-design. IEEE Antennas Wirel. Propag. Lett. 2009, 8, 141-144.

25. Hong, J.-S.G.; Lancaster, M.J. Microstrip Filters for RF/Microwave Applications; John Wiley \& Sons: Hoboken, NJ, USA, 2004; pp. 1-476.

26. Stutzman, L.W.; Thiele, G.A. Antenna Theory and Design; John Wiley \& Sons: Hoboken, NJ, USA, 2012; pp. 1-848.

27. Chen, L.; Luo, Y.-L. Compact filtering antenna using CRLH resonator and defected ground structure. Electron. Lett. 2014, 50, 496-1498. [CrossRef]

28. Kozlov, M.; Turner, R. A comparison of Ansoft HFSS and CST microwave studio simulation software for multi-channel coil design and SAR estimation at 7T MRI. Piers Online 2010, 6, 395-399. [CrossRef]

29. Chuang, C.-T.; Chung, S.-J. A new compact filtering antenna using defected ground resonator. In Proceedings of the Microwave Conference Proceedings (APMC), Asia-Pacific, Yokohama, Japan, 7-10 December 2010; pp. 1003-1006.

30. Al-Yasir, Y.I.A.; Abdullah, A.S.; Mohammed, H.J.; Mohammed, B.; Abd-Alhameed, R.A.; Noras, J. Design of Radiation Pattern-Reconfigurable 60-GHz Antenna for 5G Applications. J. Telecommun. 2014, 27, 7-11.

31. Jadhav, J.B.; Deore, P.J. Filtering antenna with radiation and filtering functions for wireless applications. J. Electr. Syst. Inf. Technol. 2017, 4, 125-134. [CrossRef]

32. Wang, K.; Zheng, L.-S.; Wong, S.W.; Zheng, Y.-F.; Chu, Q.-X. Design of even-order symmetric bandpass filter with Chebyshev response. Prog. Electromagn. Res. 2013, 42, 239-251. [CrossRef]

33. Mahmud, F.S.; Razalli, M.S.; Rahim, H.A.; Hoon, W.F.; Ilyas, M.Z. Parametric studies on effects of defected ground structure (DGS) for dual band bandstop microstrip filter. EPJ Web Conf. 2017, 162, 1-5. [CrossRef]

34. Marotkar, P.; Kapur Zade, V. To Study the Effect of DGS on Antenna Parameters. Int. J. Ind. Electron. Electr. Eng. 2015, 3, 17-20.

35. Wu, W.; Fan, R.; Wang, J.; Zhang, Q. A broadband low profile microstrip filter-antenna with an omni-directional pattern. In Proceedings of the 2014 3rd Asia-Pacific Conference on Antennas and Propagation, Harbin, China, 26-29 July 2014; pp. 580-582.

36. Lin, C.-K.; Chung, S.-J. A Compact Filtering Microstrip Antenna with Quasi-Elliptic Broadside Antenna Gain Response. IEEE Antennas Wirel. Propag. Lett. 2011, 10, 381-384.

37. Wu, W.; Ma, B.; Wang, J.; Wang, C. Design of a microstrip antenna with filtering characteristics for wireless communication systems. In Proceedings of the 2017 Sixth Asia-Pacific Conference on Antennas and Propagation (APCAP), Xi'an, China, 16-19 October 2017; pp. 1-3.

38. Wu, W.; Yin, Y.; Zuo, S.; Zhang, Z.; Xie, J. A New Compact Filter-Antenna for Modern Wireless Communication Systems. IEEE Antennas Wirel. Propag. Lett. 2011, 10, 1131-1134.

39. Ohira, M.; Ma, Z. An efficient design method of microstrip filtering antenna suitable for circuit synthesis theory of microwave bandpass filters. In Proceedings of the 2015 International Symposium on Antennas and Propagation (ISAP), Hobart, Australia, 9-12 November 2015; pp. 1-4.

40. Al-Yasir, Y.I.A.; Hasanain, A.H.A.; Baha, A.S.; Parchin, N.O.; Ahmed, M.A.; Abdulkareem, S.A.; Raed, A.A. New Radiation Pattern-Reconfigurable 60-GHz Antenna for 5G Communications. IntechOpen 2019. Available online: https:/www.intechopen.com/online-first/new-radiation-pattern-reconfigurable-60-ghz-antennafor-5g-communications (accessed on 26 September 2019). [CrossRef]

41. Al-Yasir, Y.I.A.; Parchin, N.O.; Elfergani, I.; Abd-Alhameed, R.A.; Noras, J.M.; Rodriguez, J.; Al-jzari, A.; Hammed, W.I. A New Polarization-Reconfigurable Antenna for 5G Wireless Communications. In Broadband Communications, Networks, and Systems. BROADNETS 2018. Lecture Notes of the Institute for Computer Sciences, Social Informatics and Telecommunications Engineering; Sucasas, V., Mantas, G., Althunibat, S., Eds.; Springer: Cham, Germany, 2019; Volume 263. 
42. Mohammed, K.A.; Alhamadani, A.; Al-Yasir, Y.I.A.; Saleh, A.L.; Parchin, N.O.; Abd-Alhameed, R. Study on the effect of the substrate material type and thickness on the performance of the filtering antenna design. TELKOMNIKA Telecommun. Comput. Electron. Control 2020, 18, 72-79.

43. Al-Yasir, Y.I.A.; Ojaroudi Parchin, N.; Fares, M.N.; Abdulkahaleq, A.; Bakr, M.; Al-Sadoon, M.; Kosha, J.; Abd-Alhameed, R. A Differential-Fed Dual-Polarized High-Gain Filtering Antenna Based on SIW Technology for 5G Applications. In Proceedings of the 2020 14th European Conference on Antennas and Propagation (EuCAP), Copenhagen, Denmark, 15-20 March 2020; pp. 1-5.

44. Al-Yasir, Y.I.A.; Ojaroudi Parchin, N.; Fares, M.n.; Abdulkhaleq, A.; Sajedin, M.; Elfergani, I.; Rodriguez, J.; Abd-Alhameed, R. New High-Gain Differential-Fed Dual-Polarized Filtering Microstrip Antenna for 5G Applications. In Proceedings of the 2020 14th European Conference on Antennas and Propagation (EuCAP), Copenhagen, Denmark, 15-20 March 2020; pp. 1-5.

C 2020 by the authors. Licensee MDPI, Basel, Switzerland. This article is an open access article distributed under the terms and conditions of the Creative Commons Attribution (CC BY) license (http://creativecommons.org/licenses/by/4.0/). 